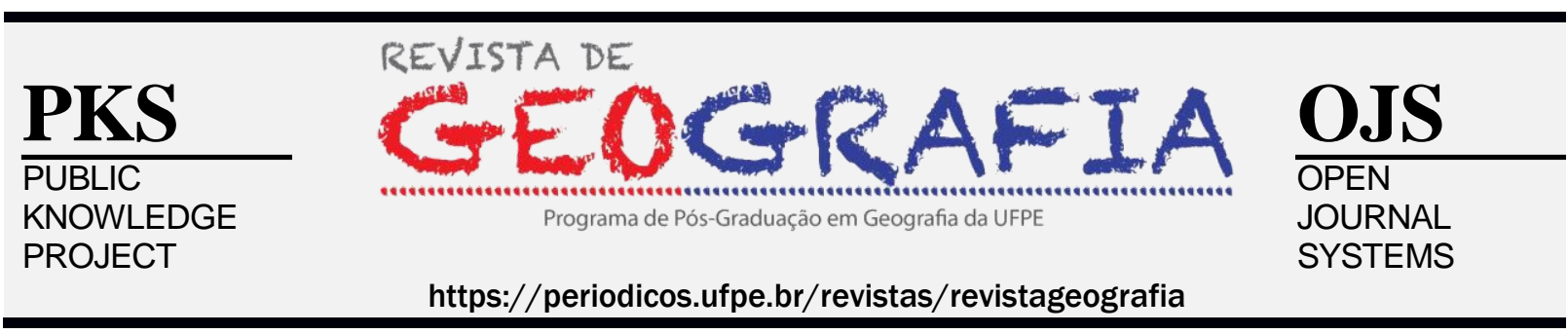

\title{
A CRIAÇÃO DE MUNICÍPIOS NO BRASIL: ENTRE AS LEIS E AS POSSIBILIDADES
}

\author{
Vládia da Silva Souza ${ }^{1}$, Francisco Amaro Gomes de Alencar ${ }^{2}$
}

${ }^{1}$ Prof. Ms. IFCE; Dotouranda em Geografia pela UFC. E-mail: vladia.souza@ifce.edu.br

${ }^{2}$ Professor do Programa de Pós-Graduação em Geografia da UFC. E-mail: famaro.ufc@gmail.com

Artigo recebido em 12/06/2019 e aceito em 25/12/2019

\begin{abstract}
RESUMO
A criação de municípios no Brasil esteve influenciada por estratégias políticas de poder. Antes da Constituição Federal de 1988, a formação de unidades políticas locais ocorria, geralmente, orientada pelo desejo dos grandes proprietários de terras interessados em manter o controle sobre a política local e a economia do Estado. Atualmente, questões como repasses constitucionais e a possibilidade de levar lideranças locais ao poder são os novos interesses que condicionam as emancipações municipais. Considerando essas estratégias, cabe avaliar a necessidade do processo de emancipação, pois se entende que, em algumas localidades, ele torna-se necessário para que seus habitantes tenham acesso aos serviços públicos com qualidade. Por esta razão, este estudo discorre sobre as emancipações municipais que ocorreram no Brasil, atentando para os atores políticos e as instituições que condicionam esse processo, tendo em mente que a criação de municípios deve ocorrer orientada para o bem comum da população e não como estratégia para angariar fundos e repasses fiscais ou permitir que grupos políticos assumam o poder.
\end{abstract}

Palavras-chave: Emancipações. Poder. População. Municípios.

\section{THE CREATION OF MUNICIPALITIES IN BRAZIL: BETWEEN LAWS AND POSSIBILITIES}

\begin{abstract}
The creation of municipalities in Brazil used to be influenced by political power strategies. Prior to the 1988 Federal Constitution, the formation of local political units was usually driven by the desire of large landowners who were interested in maintaining control over local politics as well as the state economy. Currently, issues such as constitutional transfers and the possibility of bringing local leaders to power are the new interests that condition the municipal emancipations. Considering these strategies, it is necessary to evaluate the necessity of the process of emancipation, because it is understood that in some localities, it becomes necessary for its inhabitants to have access to public quality services. That is why, this study discusses the municipal emancipations that have occurred in Brazil, being attentive to the political actors and institutions that condition such process, bearing in mind that the creation of municipalities should occur oriented to the common good of the population but not as a strategy to raise funds and tax transfers or allow that political groups take power.
\end{abstract}

Keywords: Emancipations. Power. Population. Municipalities 


\section{INTRODUÇÃO}

A discussão que se segue propõe argumentar sobre as emancipações municipais no Brasil, atentando para os dispositivos constitucionais, os atores políticos e as instituições que interferem nesse processo.

Com a promulgação da Constituição de 1988, o Brasil passou por um aumento vertiginoso no seu número de municípios, trazendo a tona discussões sobre as consequências da criação de células administrativas locais para os cidadãos.

Compreendendo o território como um conceito-chave da Geografia, entende-se que todas as relações que nele se desenvolvem fazem parte do saber geográfico. Portanto, as divisões territoriais que incitam a formação de novos limites municipais e estaduais e todas as conflitualidades que emergem desse processo, fazem parte do arcabouço teórico que abrange a ciência geográfica.

Embora, a formação de novos limites territoriais a partir da divisão de um município mãe seja um tema, por excelência, geográfico, há ainda lacunas a ser preenchidas em torno das discussões sobre o que representa as emancipações municipais. É preciso ter em mente que, independente da escala de atuação, os territórios estão imbuídos de uma dinamicidade que lhes permitem constates modificações, podendo, em qualquer momento, ser desmembrados, recriados ou passar por processos de anexação e divisão de suas áreas.

Essa dinamicidade territorial fica clara ao se deparar com exemplos como a proposta de divisão do estado do Pará nos estados de Tapajós e Carajás, além do leque de distritos emancipados de seus municípios.

Portanto, este ensaio se debruçara sobre as emancipações municipais, com a premissa de que as divisões e subdivisões territoriais que resultam na conformação de países, estados, municípios e outras configurações; não são apenas dados passivos estabelecidos por vagas políticas de organização territorial, mas sim o resultado dos interesses emergentes da vida em sociedade.

\section{OS MUNICÍPIOS BRASILEIROS: A CONFIGURAÇÃO ATUAL}

O espaço geográfico é modelado por conflitos que emergem de relações sociais e se materializam no território para organizá-lo conforme os interesses dos diversos grupos que compõem a sociedade. 
Os objetivos que esses grupos apresentam são dinâmicos, distintos e muitas vezes conflituosos, por isso pressupõem diferentes arranjos e configurações territoriais. Dessa forma, os recortes administrativos que consolidam as unidades da federação como os estados e os municípios são resultados dos interesses emergentes da vida em sociedade.

Os interesses e conflitos divergentes desses grupos materializam-se no território, fazendo emergir relações de poder fundamentais para compreensão dos processos que permeiam o quadro das emancipações municipais. Essas relações de poder são importantes, pois, assim como as divisões territoriais resultam das vontades expressas na vida social, o desejo de desmembramento do município de origem emerge do povo, que é o centro de transmissão do poder.

De acordo com Raffestin (1993), é da população que se origina o poder. Para este autor o poder está apoiado no tripé: população, território e recursos.

\footnotetext{
Considerando o que foi dito sobre a natureza do poder, será fácil compreender porque colocamos a população em primeiro lugar: simplesmente porque ela está na origem de todo poder. Nela residem as capacidades virtuais de transformação; ela constitui o elemento dinâmico de onde procede a ação. [...] O território não é menos indispensável, uma vez que é a cena do poder e o lugar de todas as relações, mas sem a população ele se resume a apenas uma potencialidade, um dado estático a organizar e a integrar uma estratégia. Os recursos, enfim, determinam os horizontes possíveis da ação. Os recursos condicionam o alcance da ação. (RAFFESTIN 1993, p. 58)
}

Seguindo este raciocínio, no processo de formação de municípios, pode-se afirmar que a população corresponde às pessoas diretamente afetadas nesse processo, o território é a área propensa ao desmembramento político-administrativo e os recursos são as bases concretas que possibilitam a efetivação da emancipação.

A necessidade de controle sobre o território e tudo o que ele agrega é o que movimenta as sociedades políticas e administrativamente organizadas. Assim, é possível compreender quando Raffestin (1993, p. 144) afirma que o território é “"[...] um espaço onde se projetou um trabalho, seja energia e informação, e que, por consequência, revela relações marcadas pelo poder".

Souza (1995, p.78) também concorda com esse raciocínio quando afirma que "O território [...] é fundamentalmente um espaço definido e delimitado por e a partir de relações de poder." Portanto, pode-se compreendê-lo como uma teia de relações sociais que são delineadas no espaço.

Outra noção de território que se mostra muito pertinente para compreender o processo de emancipação municipal é a defendida por Gottmann (2012), que discute o território 
sob uma ótica política, afirmando ser este a relação entre grupos politicamente organizados e o espaço. Segundo ele, o "Território é um conceito político e geográfico, porque o espaço geográfico é tanto compartimentado quanto organizado através de processos políticos”. (GOTTMANN, 2012 p. 526)

É quase impossível falar de território sem mencionar o limite. A tessitura territorial pressupõe a ação de um grupo interagindo nessa porção do espaço para adequá-lo aos seus objetivos. A interação desse grupo estabelece os limites dessa porção territorializada do espaço para que se possa manifestar o poder e o controle sobre ele. Os limites concretizam territorialmente as relações de poder.

No contexto em que se inserem as emancipações municipais, os limites são importantes ferramentas asseguradas por leis para delimitar os recortes administrativos e estabelecer o controle sobre a jurisdição territorial criada. No caso brasileiro, os municípios tornam-se instituições à disposição da sociedade local, definidos por limites estabelecidos na base legal da estrutura federativa do país.

Os municípios são constituídos pelo Executivo representado pelo Prefeito e pelo Legislativo equivalente à Câmara dos Vereadores. Territorialmente estão divididos em distritos, podendo apresentar vários ou somente o Distrito principal, onde se localiza a área urbana e a sede municipal.

Esta escala local do território brasileiro é significativa do fazer político e como tal, tem o fundamento de sua autonomia administrativa assegurada pelo artigo 30 da Constituição Federal de 1988, que delega aos municípios a competência para:

I - legislar sobre assuntos de interesse local; II - suplementar a legislação federal e a estadual no que couber; III - instituir e arrecadar os tributos de sua competência, bem como aplicar suas rendas, sem prejuízo da obrigatoriedade de prestar contas e publicar balancetes nos prazos fixados em lei; IV - criar, organizar e suprimir Distritos, observada a legislação estadual; V - organizar e prestar, diretamente ou sob regime de concessão ou permissão, os serviços públicos de interesse local, incluído o de transporte coletivo, que tem caráter essencial; VI - manter, com a cooperação técnica e financeira da União e do Estado, programas de educação pré-escolar e de ensino fundamental; VII - prestar, com a cooperação técnica e financeira da União e do Estado, serviços de atendimento à saúde da população; VIII - promover, no que couber adequado ordenamento territorial, mediante planejamento e controle do uso, do parcelamento e da ocupação do solo urbano; IX - promover a proteção do patrimônio histórico-cultural local, observada a legislação e a ação fiscalizadora federal e estadual. (BRASIL, 1988a)

A concepção de município perpassa a ótica da delimitação territorial onde este é compreendido como a porção circunscrita dos estados, autônoma e governada por um prefeito e uma câmara de vereadores. Isto porque o município concebe um território onde se perpetuam 
práticas políticas, sociais e culturais que propiciam o exercício da cidadania. "Afinal, a cidadania se conquista através da lei geral, mas é vivida no cotidiano do território, ou seja, naquele das relações de proximidade, de oferta e acesso aos serviços que tornam o direito uma prática social real”. (CASTRO, 2005, p. 134)

É nesta escala de atuação do poder público que se consolida o aparato institucional voltado ao desenvolvimento de políticas públicas que exercem fortes influências no território e na vida do cidadão.

O município pode ser compreendido a partir de várias esferas como: a sociológica, a política e a jurídica. Na perspectiva social, ele abrange um agrupamento de pessoas convivendo em uma mesma poção territorial e apresentando interesses comuns a satisfação das necessidades individuais e coletivas que se expressam na vida em sociedade.

$\mathrm{Na}$ esfera política, o município é uma entidade estatal de competências específicas e governo autônomo, porém, diretamente ligada ao Estado-Membro por meio de laços constitucionais. E sob o ponto de vista legal, a unidade de governo local é uma pessoa jurídica com direito público interno e capacidade para decidir sobre as questões de interesses locais, exercer seus direitos, adquirir obrigações e responder pelos atos de seus representantes. Portanto, o município, em seu contexto mais amplo, é:

\begin{abstract}
Em primeiro lugar um recorte federativo, com importante grau de autonomia - o que significa atribuições e recursos próprios - em segundo trata-se de uma escala política, ou seja, um território político por excelência, e constitui um distrito eleitoral formal para vereadores e prefeitos e informal para todas as outras eleições com consequiências importantes para a sociedade local e para o território; em terceiro, é no município que todos habitamos e exercemos nossos direitos, e deveres da cidadania, onde buscamos os serviços a que temos direito como cidadãos; onde votamos e candidatos são votados. Também é nele que são concretizadas as políticas públicas. (CASTRO, 2005, p. 135)
\end{abstract}

O município é um recorte revelador de comportamentos e valores que dão margem à apreensão das semelhanças e diferenças regionais. No Brasil, ele precedeu o próprio Estado e vem se constituindo como um dos fundamentos da sociedade até os dias atuais. Ele é um dos pilares que sustenta a democracia, pois assegura às comunidades locais o direito de se posicionar sobre os assuntos que lhes dizem respeito. Para um país com dimensões continentais como o Brasil, a existência do município é essencial para o exercício da cidadania, desde, é claro, que haja uma gestão administrativa ética, transparente, democrática e comprometida com a população. 


\section{EMANCIPAÇÕES MUNICIPAIS: Dos atores políticos às instituições}

A forma com que ocorreram as emancipações municipais foi um reflexo contexto histórico do país, associados aos mecanismos políticos e institucionais que conferiram poder de decisão sobre a administração do Estado a uma elite. Em outras palavras, a criação de municípios foi um fator condicionado aos interesses das elites locais que detinham o controle político e poder de influencia sobre o Estado. Por esta razão, antes da Constituição de 1988, ora os municípios brasileiros estavam dotados de uma centralidade política, dependendo das decisões dos governos estaduais, ora se beneficiavam de uma autonomia que lhes concediam o direito de legislar sobre as questões de interesses locais.

A Constituição de 1988 exerceu fortes influências no ritmo emancipacionista, pois a transferência da União para os Estados, do poder de decisão e regulamentação das emancipações garantiu uma descentralização política e administrativa que repercutiu positivamente na criação das unidades de governo local. Conforme Tomio (2002, p. 65), “A autonomia institucional dos Estados, na elaboração da regulamentação e na decisão política, foi o fator preponderante para o ritmo diferenciado na criação de municípios".

$\mathrm{O}$ atual contexto em que se inserem as emancipações municipais compreende um conjunto de estratégias articuladas entre os atores políticos e as instituições que movimentam as decisões necessárias para estruturar o processo emancipatório. As deliberações que regimentam a criação de municípios são definidas na esfera de governo estadual e mediadas pela ação de quatro tipos de atores políticos: as lideranças políticas locais, os eleitores, os deputados estaduais ou parlamentares e o executivo. Cada ator intervém no processo decisório com maior ou menor capacidade para definir se um distrito é emancipável ou não.

As lideranças políticas locais são grupos politizados residentes nas localidades que pleiteiam a independência político-administrativa e que têm a prerrogativa de iniciar legalmente a ação emancipacionista. De acordo com Tomio (2002), as lideranças se relacionam estrategicamente tanto com os eleitores locais, convencendo-os a se manifestarem positivamente nos plebiscitos, quanto com os deputados estaduais, fazendo pressão para que os membros da assembleia sejam favoráveis ao processo, com promessa de recompensa de votos.

Os eleitores compreendem a população eleitoral da área emancipável e participam do processo se posicionando contra ou a favor nos plebiscitos. Já os parlamentares são responsáveis por controlar o andamento das questões legislativas que regem as emancipações. 
Em geral, participam de todas as etapas necessárias à criação de municípios, podendo interromper esse processo a qualquer momento.

O quarto ator político corresponde ao executivo estadual, composto pelo Governador mais os secretários de estado. Este ator se relaciona com os parlamentares e sua principal ação nas deliberações legislativas é o poder de veto e sanção das emancipações.

Todos os quatro tipos de atores participam do processo decisório sobre a criação de municípios. Sem a iniciativa das lideranças locais [...] ou a votação plebiscitária, seria impossível haver divisão municipal. Porém, desde que o processo tenha sido iniciado, o centro decisório é deslocado para o poder executivo e para os deputados estaduais, e o resultado depende das estratégias desenvolvidas por esses atores. (TOMIO, 2002, p. $67-68)$

Embora o parecer favorável dos atores políticos à criação de municípios seja importante e necessário, ele não é suficiente para definir a emancipação municipal. A decisão dos envolvidos nesse processo depende do arranjo institucional que compreende três tipos de instituições: as delimitadoras, as processuais e as estimuladoras.

É relevante entender que atores políticos e instituições têm funções dessemelhantes no regimento das questões emancipacionistas. Enquanto os primeiros se envolvem nas decisões políticas sobre a criação de municípios, os segundos têm como responsabilidade regulamentar as etapas legais das emancipações.

Tantos s instituições delimitadoras, quanto as processuais são representadas pelo Poder Legislativo. As primeiras envolvem as esferas de governo Federal, Estadual e Municipal. Correspondem aos critérios dispostos na legislação que determinam se um território é emancipável ou não. A função deste mecanismo é definir o volume de distritos emancipáveis.

A Constituição Federal atua estabelecendo como se deve proceder ao processo emancipatório, a legislação Estadual, a partir dos dispostos na lei federal define os critérios para criação de municípios e os municípios junto com seus governantes, através de Leis Orgânicas, estabelecem as regras para a criação ou extinção de distritos.

As instituições processuais, sob a competência das esferas de governo Federal e Estadual, determinam o andamento das deliberações legislativas até a promulgação da lei de emancipação, podendo vetar ou acelerar a criação de municípios. Compete ainda, a esse conjunto de instituições, definir a possibilidade de interferência dos atores políticos durantes as etapas das emancipações. Conforme Tomio (2002, p. 70 -71), as instituições processuais:

[...] reúnem os mecanismos endógenos ao funcionamento dos parlamentos estaduais e as regras que delimitam a interação entre os atores políticos no processo legislativo de criação de um município ou de alteração da regulamentação estadual sobre os 
critérios mínimos exigidos à emancipação. Esses mecanismos moldam a interação política, constrangendo as estratégias dos atores políticos nos diversos momentos de decisão até que a lei de emancipação ou a legislação complementar seja promulgada.

As instituições estimuladoras, diferentemente das outras mencionadas, atuam na legislação que regulamenta as transferências dos recursos fiscais federais e estaduais para os municípios. A origem dos recursos regulamentados por estas instituições provém de quatro fontes: os recursos arrecadados no próprio município, como é o caso do Imposto Predial e Territorial Urbano (IPTU). As transferências dos impostos federais e estaduais gerados no próprio município, como o Imposto sobre a Propriedade de Veículos Automotores (IPVA). Os fundos estaduais e federais, como é o caso do Imposto sobre Circulação de Mercadorias e Prestação de Serviços (ICMS) e o Fundo de Participação dos Municípios (FPM). E por fim, os recursos de transferência voluntária gerados em obras, convênios etc.

A criação de municípios - desconsiderando as possibilidades de vetos e as discordâncias entre parlamentares e executivos estaduais - ocorre da seguinte forma: as instituições delimitadoras estabelecem os parâmetros a serem seguidos na criação de novas unidades de governo local. Com base nisso, as lideranças políticas locais iniciam o processo. Uma vez iniciado, cabe às instituições processuais verificar a viabilidade do pedido e aprovar ou não o plebiscito. Sendo aprovado, os leitores se manifestam contra ou a favor, uma vez favorável, cabe aos deputados estaduais aceitar o pedido de desmembramento e elaborar a lei de criação. É de responsabilidade do executivo estadual vetar ou sancionar a lei. Se aprovada, o município é criado e passa a ter o repasse dos fundos fiscais garantidos e regulamentados pelas instituições estimuladoras.

As instituições estimuladoras, por tratar diretamente da partilha das tarifas de impostos federais e estaduais, alimentam o interesse das lideranças locais e do eleitorado que visam à independência territorial político-administrativa. Por esta razão, recursos como o FPM tem sido um dos principais incentivos para a emancipação de muitos distritos.

O FPM é um fundo de verbas arrecadado pela União e repassado para os municípios e seu percentual de distribuição é determinado principalmente pelo número de habitantes existentes nas unidades de governo local. Segundo dados do Ministério da Fazenda, esse fundo é composto pelo Imposto de Renda (IR) e pelo Imposto sobre Produtos Industrializados (IPI).

A questão é que o FPM tem sido a principal fonte de recurso de alguns municípios com pequeno porte demográfico, não sendo suficiente para dar conta dos anseios da população. Estes municípios em geral, não possuem uma quantidade de contribuintes expressiva, capaz de gerar receita para os cofres municipais e por isso se tornam dependentes dos repasses federais.

$\begin{array}{llr}\text { Souza e Alencar, } 2020 . & \text { ISSN 0104-5490 }\end{array}$


Questões como essa inserem reflexões sobre a relevância das emancipações, fazendo repensar até que ponto a municipalização de distritos é necessária.

É preciso considerar que os municípios brasileiros apresentam peculiaridades, diferentes necessidades e diversos padrões de receitas e despesas. Fatores como esses devem ser ponderados na hora de se analisar a importância das emancipações municipais, para evitar que alguns distritos se tornem independentes apenas para atender aos anseios políticos de determinados grupos de poder. A independência político-administrativa de um distrito deve primar, acima de tudo, pelo bem comum da população envolvida nesse processo, pois como relata Pinto (2002, p. 19):

O atual caminho tomado pelo país, em que há uma multiplicação crescente de municípios, muitos deles inviáveis, é preocupante. É natural que, em virtude do progresso, do desenvolvimento tecnológico e econômico e da pressão exercida por diversos setores da sociedade, haja novas divisões e a criação de novos municípios. Contudo, a emancipação político-administrativa de um distrito, visando atender ao anseio de políticos e de determinados grupos do poder, com interesses próprios e particulares deve ser vista sob uma perspectiva de destruição da democracia e do Estado.

Os motivos apontados para justificar o anseio de emancipação municipal diferem de acordo com as características de cada lugar. Em geral, são apontados fatores como a existência de uma base econômica consolidada propícia à sustentação de um novo município. A grande extensão territorial do município de origem associada ao descaso pelos distritos que apresentam ausência de serviços públicos essenciais à população. Há ainda o caso de distritos que alegam estagnação econômica, afirmando que só poderiam se desenvolver mediante a independência político-administrativa.

Existem várias razões para a criação de unidades de governo local, destacando-se as de natureza política, econômica e demográfica. Sob a ótica política, esse fenômeno pode ser explicado tanto pela pressão social exercida pela população, quanto pela satisfação de interesses políticos. Em distritos populosos, onde a comunidade tem um melhor acesso a ferramentas de comunicação e informação, é normal que surjam exigências sociais pela contínua melhoria de equipamentos coletivos que satisfaçam as demandas da população. Nesse caso, pode surgir do povo uma consciência emancipatória, na medida em que se almeja uma melhora na qualidade de vida. No entanto, essa consciência também pode emanar de determinados grupos de poder interessados em ganhar popularidade e com isso angariar votos para os futuros cargos políticos. Sobre esse dois aspectos da natureza política que movimenta a criação de municípios, Pinto (2002, p. 10) explica que: 
No primeiro, há um movimento que vem "de baixo para cima", ou seja, a pressão social cria a pressão política, sendo assim muito mais democrático, uma vez que o desejo emana do povo. No segundo, há um movimento que vem "de cima para baixo", uma vez que a emancipação político-administrativa atende, de forma mais intensa, aos anseios políticos que aos desejos das populações locais.

As razões de natureza econômica são percebidas quando a questão emancipatória é explicada pelo interesse em receber diretamente os recursos fiscais, para melhor administrar os recursos públicos e assim oferecer qualidade de vida a população. Já as razões de natureza demográfica ocorrem quando o aumento da população se torna o principal motivo de emancipação.

Embora essas razões sejam bem defendidas pelos que desejam a emancipação municipal, não existem fórmulas matemáticas que possam garantir o sucesso das futuras unidades de governo local. É necessário avaliar a relevância e a necessidade dessas divisões territoriais, pois, em algumas situações, uma administração municipal de qualidade pode suprir as necessidades dos distritos, evitando possíveis divisões.

Em alguns casos, como acontece para os grandes municípios da região Norte do país, a emancipação municipal, à medida que aumente a ocupação territorial e, por consequiência, o nível de atividade econômica local, talvez seja necessária. No caso de regiões estagnadas, a emancipação irá se constituir em maiores gastos legislativos e de pessoal e provavelmente não será, sozinha, capaz de promover o desenvolvimento local. Em municípios com atividade econômica suficiente, talvez a emancipação possa ser evitada com uma mudança de cultura dos administradores dos municípios aos quais pertencem as áreas que pleiteiam a emancipação. (MAGALHÃES, 2007, p. 15)

É necessário que a administração pública municipal seja comprometida com as localidades sob sua jurisdição e promova uma distribuição das receitas que seja proporcional às despesas de cada distrito. Afinal, se todos os distritos de um determinado município for bem assistido pela gestão administrativa, a propensão em se desmembrar se torna menor.

\section{A PROBLEMÁTICA DAS EMANCIPAÇÕES MUNICIPAIS: $O$ caminho legal}

De acordo com a Constituição Federal Brasileira de 1988, o município é uma Unidade da Federação autônoma, com competência para legislar sobre as questões locais e autoridade para aplicar e arrecadar tributos próprios. Dentre outros fatores, essas características 
concedidas às unidades de governo local têm ocasionado mudanças no quadro territorial dos municípios, decorrentes do anseio de desmembramento dos distritos que os compõem. Esse processo é conhecido como emancipação político-administrativa e é definido por Pinto (2002, p. 8) como:

[...] ato através do qual um distrito torna-se um município, ou seja, deixa de estar subordinado ao município de origem e passa a constituir um novo município, com governo próprio, Prefeito e Vice-prefeito Municipal, Câmara Municipal, Vereadores, leis próprias, arrecadação de tributos e impostos próprios.

As emancipações municipais são regulamentadas por decisões políticoadministrativas e precisam de base legal que determine os critérios para criação de municípios, estipule os limites municipais e consolide o território, muito embora esse processo não seja tão ordenado, contínuo e regular como se necessita.

Antes da Carta Magna de 1988, a criação de municípios estava sob a responsabilidade da União. Os requisitos necessários à emancipação estavam assegurados por lei complementar federal. Conforme o disposto na Constituição de 1967, a Lei Complementar nº 1, de 9 de novembro de 1967, estabeleceu os critérios mínimos de população e renda pública necessários para a emancipação municipal. Independente das divergências regionais, esses critérios eram válidos para todo o país e compreendiam:

[...] população estimada, superior a dez mil habitantes ou não inferior a cinco milésimo da população existente no Estado; eleitorado não inferior a 10 por cento da população; centro urbano já constituído, com o mínimo de duzentas casas; arrecadação mínima de cinco milésimos da receita estadual de impostos, computada no exercício anterior ao processo de emancipação. Comprovado o atendimento à tais exigências, a Assembleia Legislativa do respectivo Estado determinava a realização do plebiscito e, havendo resultado favorável, editava a lei de criação do novo município. (LORENZETTI, 2003, p. 3)

Durante a vigência dessa constituição, poucos municípios foram criados no Brasil, pois além de seu caráter centralizador, os critérios bastante restritivos excluíam do processo emancipatório as regiões com baixo índice de população e de rentabilidade econômica, como é o caso do norte e nordeste brasileiro.

A promulgação da Constituição de 1988 mudou esse cenário, pondo fim ao Poder Central e concedendo aos estados a autoridade para regulamentar o processo de emancipação municipal, como se pode ver no $\S 4^{\circ}$ do artigo 18 dessa Carta Magna:

Art. 18, $\S 4^{0}$ A criação, a incorporação, a fusão e o desmembramento de Municípios preservarão a continuidade e a unidade histórico-cultural do ambiente urbano, far-se- 
ão por lei estadual, obedecidos os requisitos previstos em lei complementar estadual, e dependerão de consulta prévia, mediante plebiscito, às populações diretamente interessadas. (BRASIL, 1988a, grifo nosso)

Com essa constituição os estados perderam o poder de interferir nas decisões internas dos municípios, mas passaram a controlar as transferências do ICMS que, junto com o FPM, é a principal fonte de renda das pequenas unidades de governo local. Os municípios passaram a legislar sobre a formação de distritos, adquiriram competência tributária própria e ampliaram a participação na arrecadação de impostos federais e estaduais. Porém, também tiveram que expandir suas obrigações com a prestação de serviços públicos essenciais.

No entanto, se por um lado a Constituição de 1967 era restritiva, autoritária e ditatorial, a Carta Magna de 1988 revelou-se permissiva e consequentemente danosa aos cofres públicos, pois a maioria das leis complementares estaduais redigidas para regulamentar o disposto no $\S 4^{\circ}$ do artigo 18 , estabeleciam critérios que facilitavam a criação de municípios.

Sob estas circunstâncias, inúmeros municípios foram criados. Muitos deles, com o intuito de atender aos interesses de grupos políticos do poder local. Esses municípios surgiram sem a existência de uma receita própria que garantisse a sua autossustentabilidade e se tornaram dependentes dos repasses fiscais provindos da União e dos estados. De acordo com Lorenzetti (2003, p. 4), o número de municípios aumentou de maneira exorbitante,

[...] em 1980 existiam no País 3.974 municípios instalados, montante que passou a 4.090 em 1984, o que significa um crescimento de cerca de 3\%. Em 1996 a Contagem da População realizada pelo IBGE apontava a existência de 4.974 municípios instalados e outros 573 aguardando instalação, ou seja, um acréscimo de aproximadamente $22 \%$ desde 1984 . Ainda segundo o IBGE, por ocasião do senso de 2000, o número de municípios atingia 5.561, dos quais 5.507 instalados e 54 aguardando instalação. Desnecessário mencionar que o PIB nacional (assim como arrecadação de receitas públicas) não cresceu na mesma proporção nesse período, que significa dizer que as fatias de receita de cada município ficaram menores.

Na tentativa de estabelecer restrições ao processo de emancipação municipal, o Congresso Nacional promulgou em 12 de novembro de 1996 a Emenda Constitucional $n^{\circ} 15$, que deu nova redação ao $\S 4^{\circ}$ do artigo 18 da Carta Magna. A partir dessa emenda, este dispositivo constitucional passou a vigorar com o seguinte texto:

Art. 18, $\$ 4^{0}$ A criação, a incorporação, a fusão e o desmembramento de Municípios, far-se-ão por lei estadual, dentro do período determinado por lei complementar federal, e dependerão de consulta prévia, mediante plebiscito, às populações dos Municípios envolvidos, após divulgação dos Estudos de Viabilidade Municipal, apresentados e publicados na forma da lei. (BRASIL, 1988b, grifo nosso) 
Como se pode perceber, as emancipações municipais continuam sob a responsabilidade da instância legislativa estadual. Porém, a partir desse dispositivo passa haver a necessidade de uma lei complementar federal que estabeleça critérios gerais sobre como proceder ao processo de criação, incorporação, fusão e desmembramentos de municípios e determine o intervalo de tempo no qual essas ações sejam possíveis de ser efetivadas.

Além de reduzir o ritmo emancipacionista, essa norma constitucional passou a exigir a realização de estudos de viabilidade para comprovar se o distrito que pleiteia a emancipação tem condições de se manter enquanto município. Conforme Noronha (1996), o ponto mais restritivo desse dispositivo foi o fato de se estender a consulta plebiscitária ao conjunto de eleitorado tanto da área que requer a independência político-administrativa, quanto do município de origem.

O fato é que, desde que a Emenda Constitucional $n^{\circ} 15$ foi promulgada, quase não se tem emancipações no Brasil, isto porque a lei complementar federal exigida neste dispositivo constitucional ainda não foi redigida ${ }^{1}$.

Para resolver a situação dos distritos brasileiros que visam à independência políticoadministrativa, desde a promulgação da norma $n^{\circ}$ 15/1996 alguns projetos de leis discorrendo sobre os estudos de viabilidade municipal, os plebiscitos e o período para criação, incorporação, fusão e desmembramento de municípios foram apresentados ao Congresso Nacional, destacando-se neste ensaio o PLS 98/2002 e PLS 104/2014.

A proposta do PLS 98/2002, foi apresentada ao Senado Federal no dia 23 de abril de 2002 e passou onze anos em tramitação entre o Senado e Câmara dos Deputados ${ }^{2}$ até ser encaminhada para apreciação da ex-presidente Dilma Rousseff, no final de 2013. Em tese, tratou-se de um arcabouço legal para regulamentar, nos termos do $\S 4^{\circ}$ do artigo 18 da Carta Magna, o processo de criação, incorporação, fusão e desmembramento de municípios.

\footnotetext{
${ }^{1}$ Porém, mesmo sem o devido amparo legal, foram criados no Brasil alguns municípios após a promulgação da Emenda Constitucional $n^{\circ} 15$. Apesar de movidas algumas ações de inconstitucionalidade para rever o caso dessas células que foram formadas, a solução encontrada pelo legislativo para regulamentar esses casos, foi incluir no texto da Emenda Constitucional n ${ }^{\circ} 57$ de dezembro de 2008 uma disposição para convalidar os atos de criação de municípios publicados até dezembro de 2006, mesmo sem a verificação de requisitos previstos em normas legais. Com essa ação, resolveu-se o caso dos municípios inconstitucionais.

2 O PLS 98/2002 foi encaminhado para apreciação na Câmara dos Deputados no dia 17 de outubro de 2008. Nesta casa esse projeto é chamado Projeto de Lei Complementar (PLP) 416/2008.
} 
A proposta apresentou certo rigor no que diz respeito ao processo de emancipação municipal, pois compreendeu normas para um estudo de viabilidade condizente com a finalidade de comprovar se o distrito teria condições para se tornar administrativamente independente. Além disso, assistiu o município pré-existente, na medida em que estabeleceu indenizações por contas das dívidas contraídas para beneficiar o território desmembrado. Também assegurou que a célula administrativa remanescente não apresentasse defasagem populacional após o desmembramento e impedia a emancipação se esta prejudicasse a viabilidade da condição de município da célula mãe.

No entanto, também notou-se nesse projeto alguns critérios que deixaram a desejar, como é o caso dos baixos índices populacionais exigidos para que um distrito se torne município. O indicador demográfico é um dos principais critérios para a criação de novas unidades de governo local. Com o PLS 98/2002, um distrito da região nordeste com aproximadamente 8 mil habitantes e estando em conformidade com as outras exigências, já teria condições para se autogovernar. O problema é que o baixo índice demográfico permitiria a emancipação de muitos distritos pequenos e não se sabe até que ponto um município com poucos habitantes teria condições de se autogerir. Além do mais, a maioria dos distritos brasileiros pouco populosos não tem capacidade arrecadatória suficiente para se manter como município.

Levantamentos da União Brasileira em Defesa da Criação de Novos Municípios (UBDCNM) apontaram uma média para o Brasil de 188 distritos em condições de se emancipar, conforme as regras do PLS 98/2002. Dessa estimativa, Maranhão, Bahia e Ceará lideraram o processo de criação de municípios com respectivamente 32,28 e 26 distritos atendendo as normas desse projeto (NERI, 2013). No entanto, nas análises feitas pelo Instituto de Pesquisa Econômica Aplicada (IPEA) junto às Assembleias Legislativas estaduais, o número de distritos emancipados ficaria em torno de 400, bem acima do número estimado pela UBDCNM.

Temendo um aumento excessivo do número de municípios do país, no dia 14 de novembro de 2013 a, então, presidente Dilma Rousseff vetou integralmente a proposta do PLS 98/2002, alegando que o acréscimo de novas unidades de governo local poderia ampliar demasiadamente as despesas com a manutenção da estrutura administrativa e representativa dos municípios. Alegou ainda que as receitas de arrecadação não cresceriam na mesma proporção que os gastos públicos e isso ocasionaria impactos negativos sobre a estabilidade macroeconômica. Ainda assim, a distribuição do FPM, acrescentando as novas células autônomas, prejudicaria os municípios pequenos que são dependentes desse fundo. 
Houve algumas tentativas de derrubar o veto presidencial, mas sem obter êxito, no dia 26 de março de 2014 foi apresentado ao Senado o PLS 104/2014: uma nova proposta com objetivo de alterar o conteúdo do PLS 98/2002 nos termos que levaram a, então, Presidente da República a vetar essa proposição.

Conforme a proposta inicial, aprovada no Senado no dia 14 de maio de 2014, para a criação de municípios seria necessário a comprovação de um quantitativo populacional mínimo de 6 mil habitantes para as regiões Norte e Centro-Oeste, 12 mil para a região Nordeste e 20 mil para o Sul e o Sudeste. Além da exigência de um núcleo urbano com número de imóveis superior a média encontrada nos municípios com $10 \%$ de menor população do Estado. Já a área territorial não poderia ser inferior a $200 \mathrm{~km}^{2}$ nas regiões Norte e Centro-Oeste e a $100 \mathrm{~km}^{2}$ nas regiões Nordeste, Sul e Sudeste.

Aliado à elevação do número de habitantes, a definição de uma área territorial mínima era o critério mais rigoroso dessa proposta, responsável por impedir a emancipação de distritos muito pequenos, em termos de área.

A proposta também ofereceu maior incentivo para as situações de fusão e incorporação de municípios, buscando atender o problema das unidades de baixa viabilidade econômica, pois permitia que municípios pequenos e com pouca rentabilidade se tornassem unidades maiores.

No entanto, a probabilidade de um município ser formado por fusão, ou ter sua área ampliada por incorporação de outras áreas, é menos comum que o anseio de emancipação. Isto porque quando um distrito se torna administrativamente independente ele passa a receber alíquota individual do FPM. Porém quando dois municípios se unem dando origem a uma nova célula administrativa, esta sofre perda das receitas, decorrente da aglutinação de suas áreas, pois não há um somatório das cotas do FPM dos municípios que se fundiram. A cota individual passa a ser calculada considerando a célula administrativa que surgiu da fusão.

Sobre esta condição, o PLS 104/2014 procurou estimular ainda mais as fusões e incorporações de municípios, determinando que por um período de doze anos seguintes a esses processos, as células administrativas formadas pela fusão ou ampliadas pela incorporação de áreas continuassem recebendo a cota individual do FPM como se estivessem separadas. Segundo o relator do projeto no Senado, senador Valdir Raupp, essa medida permitiria que as unidades fundidas tivessem tempo hábil para se organizar administrativamente, de forma que no futuro estivesse aptas a se autogerir com uma participação menor do FPM. 
Entende-se que incentivar o processo de fusão e incorporação de municípios é importante porque essas são medidas que custam menos aos cofres públicos da União se comparadas à criação de unidades de governo local. A fusão e a incorporação permitem um aproveitamento da estrutura político-administrativa dos municípios envolvidos, dispensando a criação de cargos públicos, sendo necessário apenas readequar os cargos existentes. Além disso, se nos termos desse projeto houvesse casos de fusão ou de incorporação de municípios, a tendência seria, em médio prazo, a redução dos repasses individuais do FPM.

A proposta do PLS 104/2014 foi encaminhada no dia 15 de maio de 2014 para apreciação na Câmara dos Deputados ${ }^{3}$, que aprovou o projeto com duas alterações: a retirada do dispositivo que estabelecia o limite territorial mínimo para as regiões brasileiras e a exigência para que o número de imóveis fosse calculado com base na área territorial urbana e rural. A proposta substitutiva na Câmara dos Deputados retornou ao Senado que acatou as alterações e no dia 5 de agosto de 2014 aprovou o projeto e o encaminhou para apreciação presidencial no dia 6 de agosto de 2014.

Mesmo o PLS 104/2014 apresentando um texto mais criterioso, no dia 26 de agosto de 2014 a ex-presidente Dilma Roussef vetou essa proposição, afirmando que o projeto aprovado no Congresso provocaria o aumento das despesas com as novas estruturas municipais e não se tem certeza se essas despesas seriam compensadas pelo aumento das receitas geradas nas novas unidades de governo local, o que poria em risco a responsabilidade fiscal do país.

Diante do hiato jurídico que o Brasil enfrenta desde 1996, por conta da ausência de uma legislação para regulamentar esse assunto, acredita-se que é necessário uma lei criteriosa que estabeleça parâmetros tanto para definir o estoque de localidades emancipáveis quanto para resolver a situação dos inúmeros municípios brasileiros cujas receitas próprias não chegam a $10 \%$ do orçamento. Por esta razão, é pertinente a existência de uma lei federal que considere os atenuantes políticos, econômicos e sociais que influenciam na vida em sociedade.

\section{CONCLUSÃO}

A intensidade com que as emancipações municipais se processaram no Brasil foi uma consequência do contexto histórico brasileiro. Em momentos de maior descentralização

\footnotetext{
${ }^{3}$ Nesta casa, essa proposta recebe o nome de PLP 397/2014.
} 
do poder, notou-se uma demanda crescente na criação de municípios, enquanto nos períodos em que o poder esteve centralizado, percebeu-se certa rigidez nesse processo.

O regime ditatorial que antecedeu a Carta Magna de 1988 foi caracterizado por uma forte centralização do poder político-administrativo nas mãos da União. Durante esse período, poucos municípios foram criados, pois a Constituição vigente, nesse momento, estabelecia critérios restritivos, que excluía do processo emancipatório diversas localidades das regiões Norte e Nordeste.

A redemocratização do país com a promulgação da Constituição de 1988 suou positivamente no quadro das emancipações municipais, uma vez que os estados ganharam autonomia institucional para deliberar sobre as questões de criação de células administrativas locais.

No período de 1990 a 1996 o Brasil registrou um aumento significativo no número de municípios, fato que se revelou danoso aos cofres da União, pois muitas das células criadas não tinham capacidade arrecadatória própria e tornaram-se dependentes dos repasses federais.

Para frear o processo de emancipação municipal, o Congresso Nacional, em 1996, promulgou a Emenda Constitucional $n^{\circ} 15$, dando nova redação ao $\S 4^{\circ}$ do artigo 18 da Carta Magna. Por meio deste dispositivo, a criação de municípios continuava sob responsabilidade da instância legislativa estadual, porém só poderá ser efetivada após a edição de uma lei complementar federal que delibere sobre o processo de emancipação.

A promulgação da norma $n^{\circ}$ 15/1996 estagnou a criação de município no Brasil e desde então, alguns projetos leis foram elaborados para cumprir o determinado nessa emenda, porém sem obter êxito. Portanto, conclui-se que diante do hiato jurídico que o país enfrenta, é necessária a promulgação da lei federal que regulamentará as emancipações municipais e estabelecerá critérios sólidos para evitar divisões territoriais inviáveis. O Brasil carece da aprovação de uma lei que delibere sobre as emancipações, considerando os atenuantes políticos, econômicos e sociais que influenciam na vida em sociedade.

\section{REFERÊNCIAS}

BRASIL. Constituição (1988a). Constituição da República Federativa do Brasil: promulgada em 5 de outubro de 1988. Brasília - DF: Senado Federal: Secretaria Especial de Informática, $2013 . \quad$ Disponível em: 
<http://www.senado.gov.br/legislacao/const/con1988/con1988_05.10.1988/ｃon1988.pdf>. Acesso em: 15 dez. 2018.

. Constituição (1988b). Emenda Constitucional no 15, de 12 de setembro de 1996.

Disponível em:

<http://www.planalto.gov.br/ccivil_03/constituicao/Emendas/Emc/emc15.htm>. Acesso em: 15 ago. 2018.

. Senado Federal. Substitutivo da Câmara ao Projeto de Lei do Senado nº 98/2002.

Dispõe sobre o procedimento para a criação, a incorporação, a fusão e o desmembramento de Municípios, nos termos do $\S 4^{\circ}$ do art. 18 da Constituição Federal. Disponível em: < https://www25.senado.leg.br/web/atividade/materias/-/materia/113088>. Acesso em: 15 ago. 2018.

. Senado Federal. Substitutivo da Câmara ao Projeto de Lei do Senado n 104/2014. Dispõe sobre o procedimento para a criação, a incorporação, a fusão e o desmembramento de Municípios, nos termos do $\S 4^{\circ}$ do art. 18 da Constituição Federal. Disponível em: < https://www25.senado.leg.br/web/atividade/materias/-/materia/118221>. Acesso em: 15 ago. 2018.

CASTRO, Iná Elias de. Geografia e política: território, escalas de ação e instituições. Rio de Janeiro: Bertrand Brasil, 2005.

GOTTMANN, Jean. Evolução do conceito de território. Boletim campineiro de Geografia, Campinas - SP, v. 2, n. 3, p. 523-545, 2012. Disponível em: < $<$ http://webcache.googleusercontent.com/search?q=cache:vnmNJIFJIV0J:agbcampinas.com.b r/bcg/index.php/boletim-

campineiro/article/download/86/2012v2n3_Gottmann/+\&cd=1\&hl=pt-BR\&ct=clnk\&gl=br $>$. Acesso em: 9 out. 2018.

LORENZETTI, Maria Silvia Barros. Criação, incorporação, fusão e desmembramento de municípios. Brasília - DF: Câmara dos Deputados, Consultoria Legislativa, 2003. Disponível em: $<$ http://www2.camara.leg.br/documentos-epesquisa/publicacoes/estnottec/pdf/305317.pdf>. Acesso em: 25 set. 2018.

MAGALHÃES. João Carlos. Emancipação político administrativa de municípios no Brasil. In: CARVALHO, Alexandre Xavier Ywata et al. Dinâmica dos municípios. Brasília: IPEA, 2007. Disponível em: < <http://ipea.gov.br/agencia/images/stories/PDFs/livros/Capitulo1_30.pdf>. Acesso em: 20 ago. 2018. 
NERI, Felipe. MA, BA e CE podem liderar criação de novos municípios, diz estudo. G1, Brasília, 19 out. 2013. Disponível em: < <http://g1.globo.com/politica/noticia/2013/10/novalei-pode-gerar-mais-municipios-em-ma-ba-e-ce-diz-levantamento.html>. Acesso em: 28 ago. 2018.

NORONHA, Rudolf de. Criação de municípios: o processo ameaçado. Revista de Administração Municipal, Rio de Janeiro, v. 43, n. 219, p. 110-117, abr./dez. 1996.

PINTO, Georges José. Município, descentralização e democratização do governo. Caminhos de Geografia, Uberlândia-MG, v. 6, n. 3, p. 1-21, jun. 2002. Disponível em:< www.seer.ufu.br/index.php/caminhosdegeografia/article/viewFile/15292/8591>. Acesso em: 17 out. 2018.

RAFFESTIN, Claude. Por uma geografia do poder. São Paulo: Ática, 1993.

SOUZA, José Marcelo Lopes de. O território: sobre o espaço e poder, autonomia e desenvolvimento. In: CASTRO, Iná Elias de; GOMES, Pedro Cesar da Costa; CORRÊA, Roberto Lobato. (Org.). Geografia: conceitos e temas. Rio de Janeiro: Bertrand Brasil, 1995. p. 77-116.

TOMIO, Fabricio Ricardo de Limas. A criação de municípios após a Constituição de 1988. Revista brasileira de ciências sociais, São Paulo, v. 17, n. 48, p. 61-90, fev. 2002. Disponível em:

<http://www.scielo.br/scielo.php?pid=S0102-69092002000100006\&script=sci_arttext>. Acesso em 13 nov. 2013. 